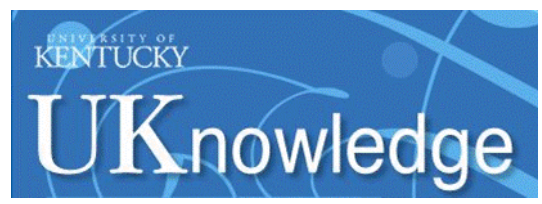

University of Kentucky

UKnowledge

Nursing Faculty Publications

College of Nursing

$7-2013$

\title{
Support for a Smoke-Free Bylaw in Parks and on Beaches
}

\author{
Chizimuzo T.C. Okoli \\ University of Kentucky, ctokol1@uky.edu \\ Ann Pederson \\ British Columbia Centre of Excellence for Women's Health, Canada \\ Wendy Rice \\ British Columbia Centre of Excellence for Women's Health, Canada
}

Follow this and additional works at: https://uknowledge.uky.edu/nursing_facpub

Part of the Nursing Commons, and the Public Health Commons

Right click to open a feedback form in a new tab to let us know how this document benefits you.

\section{Repository Citation}

Okoli, Chizimuzo T.C.; Pederson, Ann; and Rice, Wendy, "Support for a Smoke-Free Bylaw in Parks and on Beaches" (2013). Nursing Faculty Publications. 17.

https://uknowledge.uky.edu/nursing_facpub/17

This Article is brought to you for free and open access by the College of Nursing at UKnowledge. It has been accepted for inclusion in Nursing Faculty Publications by an authorized administrator of UKnowledge. For more information, please contact UKnowledge@lsv.uky.edu. 


\section{Support for a Smoke-Free Bylaw in Parks and on Beaches}

\section{Digital Object Identifier (DOI)}

http://dx.doi.org/10.1016/j.healthpol.2013.03.018

\section{Notes/Citation Information}

Published in Health Policy, v. 111, issue 2, p. 127-134.

(c) 2013 Elsevier Ireland Ltd.

This manuscript version is made available under the CC-BY-NC-ND 4.0 license

http://creativecommons.org/licenses/by-nc-nd/4.0/ 
(C) 2013 Elsevier Ireland Ltd.

This manuscript version is made available under the CC-BY-NC-ND 4.0 license

http://creativecommons.org/licenses/by-nc-

nd/4.0/ 


\title{
Support for a smoke-free bylaw in parks and on beaches
}

\author{
Chizimuz T.C. Okoli ${ }^{\mathrm{a}}$ \\ Ann Pederson ${ }^{\mathrm{b}}$ \\ Wendy Rice ${ }^{b}$
}

a 315 College of Nursing Building, University of Kentucky, Lexington, KY 40536-0232, USA

${ }^{\text {b} E 311-4500 ~ O a k ~ S t r e e t, ~ B o x ~} 48$ British Columbia Centre of Excellence for Women's Health, Vancouver, BC V6H 3N1, Canada 


\begin{abstract}
Background In September 2010, Vancouver, Canada enacted a smoke-free bylaw in parks and on beaches.
\end{abstract}

Objective To examine demographic and attitudinal factors associated with the public opinion on Vancouver's outdoor smoke-free bylaw.

Methods From 496 randomly selected Vancouver residents, information on demographics, smoking status, and opinions and support for or opposition to the smoke-free bylaw were obtained by telephone surveys.

Results Approximately $84.2 \%$ of the sample endorsed the legislation; a greater proportion of non-smokers supported the bylaw than smokers (88.6\% vs. $52.0 \%)$. In multivariate analysis, demographic variables significantly associated with supporting the smoke-free bylaw were being female, having completed Community College/University or Post Graduate work (as compared to high school education or less), and being a smoker. Furthermore, adjusting for demographic variables, all opinions regarding the smoke-free bylaw were significantly associated with its support, with the exception of the belief that the bylaw would increase stigma towards smokers.

Conclusion These findings suggest strong public support in Vancouver for the smoke-free bylaw in parks and on beaches. Jurisdictions considering such legislation should address attitudes which can promote or hinder its adoption. Examination of such policy support on diverse groups within the population may enhance the development of equitable public health policy.

Key words: secondhand smoke; smoke-free legislation; public opinion; policy analysis 
Introduction

Secondhand tobacco smoke (SHS) exposure is a significant cause of respiratory and cardiovascular diseases, and cancer $[1,2]$, contributing to an estimated 603,000 deaths globally in 2004 [3]. Smoke-free policies are one of the most important and effective strategies used in tobacco control to combat the disease burden associated with tobacco use and SHS exposure. Taken together with other strategies used in a comprehensive approach to SHS reduction (e.g., cigarette tax increases, increasing access to cessation resources, de-normalization), smoke-free policies are related to direct improvements in air quality, health, and reductions in smokingrelated behaviour [4].

To date, the majority of smoke-free policies target public indoor settings such as workplaces, bars and restaurants or outdoor spaces adjacent to indoor settings such as entryways and outdoor patios of restaurants [5,6]. With the successful tobacco control efforts to prohibit smoking in public spaces (beginning primarily with efforts in California in the 1990's), in the mid 2000's tobacco control began targeting outdoor spaces [4]. California extended its comprehensive smoke-free policies in public buildings to areas within 20 feet of main entranceways, operable windows, and exits in 2004 [4]. Another city, Calabasas, California instituted a local ordinance prohibiting smoking in all public spaces including bars, restaurants, stadiums, parks, and streets and sidewalks [7]. In 2006, Queensland, Australia became one of the first jurisdictions to institute a comprehensive ban on smoking in parks and on beaches, thereby broadening the social and physical reach of smoke-free policy [8]. Since then, jurisdictions throughout the world have begun to enact smoke-free bylaws and regulations restricting smoking in outdoor public spaces [5] such as children's playgrounds, parks, beaches and related facilities. Such smoke-free policies have now been introduced in Canada, Australia, 
the U.S., Hong Kong, New Zealand, Thailand, India, and Singapore [6, 9]. However, there is little prospective research examining public opinion with respect to smoke-free bylaws in parks and on beaches, the effectiveness of such bylaws, and how these policies may differentially affect various members of the community.

Like many developed countries, the overall prevalence of smoking in Canada is low $(18 \%)$ and is decreasing [10], but continues to remain elevated among those with low income and/or low education [11], young adults [10], and individuals who identify as aboriginal [12]. With a historically strong anti-tobacco movement Canada is an important leader in tobacco control efforts and policy globally [13]. Although smoke-free legislation varies in strength and scope across Canadian jurisdictions, such legislation primarily restricts smoking in indoor public spaces and adjacent areas [14]. The reasons commonly asserted in support of advocating smokefree policies for outdoor spaces such as parks and beaches include reducing litter, the risk of fires, the perception that smoking is a normative behavior (particularly on youth), and the potential harms associated with SHS exposure in public places [15]. In the International Agency of Research on Cancer (IARC) Handbook on Cancer Prevention and Tobacco Control review, support for smoking restrictions in parks globally $(\mathrm{N}=7$ studies addressing support for smoking restrictions) ranges from $25 \%$ in the USA (2001) to up to $83 \%$ in a New Zealand city (2007)[4]. However, few studies in Canada have examined public opinions regarding smoke-free policies in outdoor recreational areas $[5,16]$. This limited understanding in Canada of the public opinion on factors contributing to support for such bylaws or their effects presents a challenge to determining whether there are limits to the potential expansion of smoke-free policies or what could enhance the effectiveness of such bylaws. 
Vancouver is Canada's third largest city, with a population of approximately 600,000 people, although the Metro Vancouver region numbers over two million. On September 1, 2010 a smoke-free bylaw banning smoking of any substance in the city's parks, beaches and recreational facilities was implemented. There was local government and park board support for the introduction of the bylaw. This paper reports on the results of a telephone survey of public opinion regarding the adoption and implementation of the smoke-free bylaw in Vancouver. The survey was conducted as part of a larger study on the equity effects of the smoke-free bylaw, and examined demographic and attitudinal factors associated with supporting or opposing the new smoke-free bylaw in parks and on beaches in Vancouver. Understanding why different demographic factors affect support may help policy makers and advocates tailor advocacy campaigns to address the specific concerns of different subpopulations.

\section{Methods}

Design and sample

This study employed a cross-sectional analysis of survey data from residents of Vancouver, BC. Telephone surveys of residents were conducted through a survey research company (NRG Research Group) using a random digitalized calling sampling procedure. The surveys were conducted between September 15th and 25th, 2011, approximately one year after the smoke-free bylaw in parks and beaches came into effect in Vancouver. Calls were conducted according to the following schedule: Monday to Thursday (between 3pm to 8pm), Friday (3pm6pm), and Saturday and Sunday (11am to 6pm). A total of 13,394 people were randomly called with the goal to select 500 eligible and willing study participants. Eligibility criteria included residence in Vancouver, being 19 years or older and having visited a park or beach at least once in the past 12 months. 
Measures

Support for the smoke-free bylaw: Using a 4-point Likert scale participants rated their support for the bylaw by responding to the question, "Would you say that you strongly support, somewhat support, somewhat oppose, or strongly oppose smoke-free bylaws in parks and beaches in your city?" Responses were dichotomized into 'supporting' (strongly/somewhat support) and 'opposing' (somewhat/strongly oppose) the smoke-free bylaw.

Opinions regarding the smoke-free bylaw: Participants were asked a series of questions to assess their opinions about the effects of the smoke-free bylaw. These questions were:

Do you believe that smoke free bylaws in parks and beaches will:

a) Decrease the amount of cigarette litter in parks and beaches in your city?

b) Increase more negative attitudes (stigma) towards smokers?

c) Protect the health of non-smokers (including children) who visit parks and beaches?

d) Encourage people to quit smoking?

e) Discourage youth from starting smoking?

f) Infringe on the rights of smokers?

g) Protect people from exposure to secondhand smoke?

Participants reported their opinions using a 4-point Likert scale consisting of 'strongly believe'; 'somewhat believe'; 'somewhat disbelieve'; and 'strongly disbelieve'. For analysis, we dichotomized responses to each question to obtain opinions about the smoke-free bylaw into 'believing' (strongly/somewhat believe) and 'disbelieving' (somewhat/strongly disbelieve). 
Demographic: Information was obtained on sex (male or female), ethnicity (white or European Ancestry, black or African Ancestry, First Nations, South East Asian, East Asian, Middle Eastern, Hispanic or from South America, and other), age (18-34 yrs, 35-54 yrs, 55 yrs and older), marital status (never married, divorced, separated, widowed, living with spouse or partner), education status (high school or less, some community college/university, college/university graduate, post graduate degree), and living with a smoker (yes vs. no). To determine smoking status, we asked participants whether they had smoked in the past 30 days, with the response choices, 'yes' or 'no'.

Data analysis

Four participants did not respond to the question regarding their support of the smokefree law and were deleted from further analysis; thus analysis is based on responses from 496 participants. Univariate analysis employing frequencies was used to describe the study participants. Since our sample was restricted to only residents of Vancouver who met the criteria of having visited a park or a beach at least once in the previous year and were 18 years and older, we did not apply any weighting to the data. Chi-square analyses were used to examine differences between smokers and non-smokers on all study variables. We also employed a twostep model building procedure [17] to determine demographic variables to include in a logistic model assessing variables associated with support for the smoke-free law. In the first step, univariate logistic regression analyses were used to determine the unadjusted association between support for the smoke free law and all demographic variables. In the second step, only variables that were associated with support for the smoke free law (alpha $\leq .20)$ were included in the final multivariate model. Finally, we developed a second model to examine opinions about 
the smoke free law that were associated with support for the smoke-free law adjusting for demographic variables. The Hosmer-Lemeshow goodness of fit test was used to assess the fit of each model with greater p-values indicating better fitting models. All analyses were performed using the PASW Statistics 20.0 (SPSS, Inc., 2009, Chicago, IL, USA www.spss.com).

\section{Results}

Sample description

Table 1 provides a description of the sample stratified by support for the smoke-free bylaw. The sample $(n=496)$ was primarily female $(61.1 \%), 35$ years of age or older $(89.7 \%)$, and identified themselves as being 'white or European' ancestry (77.9\%). The vast majority of respondents were non-smokers $(89.9 \%)$ and few individuals lived with a smoker $(10.1 \%)$. The majority were living with a spouse or partner $(62.1 \%)$ and had greater than a high school education $(87.2 \%)$.

\section{Opinions regarding the smoke-free bylaw}

Figure 1 illustrates opinions regarding the smoke free bylaw stratified by smoking status. As compared to smokers, non-smokers were significantly more likely to believe that a smokefree bylaw would protect people from SHS exposure (87.5\% vs. 52.0\%), discourage youth from initiating smoking (50.3\% vs. $32.7 \%)$, encourage quitting (52.3\% vs. $22.0 \%)$, and protect the health of non-smokers (85.6\% vs. 56.0\%). Both non-smokers and smokers agreed, however, that smoke-free bylaws will decrease the amount of cigarette-related litter in parks and on beaches (88.9\% vs. $84.0 \%)$. As compared to non-smokers, smokers were more likely to believe that the smoke-free bylaw would infringe on the rights of smokers $(71.4 \%$ vs. $39.0 \%)$, while both 
smokers and non-smokers agreed that the smoke-free law could increase more negative attitudes (stigma) towards smokers $(75.5 \%$ vs. $69.0 \%)$.

\section{Support for the by-law}

The univariate analysis indicated that $84.2 \%$ of the sample supported the smoke-free bylaw. Significantly more supporters of the law were women as compared to men $(64.4 \%$ vs. 35.6\%). A greater proportion of those who were never married or divorced/separated/widowed opposed the law. Moreover, a greater proportion of smokers supported the law as compared to the proportion who opposed (52.0\% vs. $48.0 \%)$.

Table 2 presents the results of a two-step model building procedure to determine demographic variables that were associated with support for the smoke-free bylaw. In the first step of the analysis, all variables with the exception of age categories were associated with support for the smoke-free law at alpha $\leq .20$. In the second step $(n=447$, Hosmer-Lemeshow goodness of fit $\chi 2=2.8(\mathrm{df}=8), \mathrm{p}=.948)$ significant associations with the smoke-free law was being female as compared to male $(\mathrm{OR}=2.8,95 \% \mathrm{CI}=1.5-5.1)$, graduates of Community College/University $(\mathrm{OR}=2.5,95 \% \mathrm{CI}=1.1-5.5)$ or Post Graduate $(\mathrm{OR}=2.5,95 \% \mathrm{CI}=1.0-6.0)$ as compared to those with a high school education or less, and being a nonsmoker as compared to a smoker $(\mathrm{OR}=6.1,95 \% \mathrm{CI}=2.9-12.7)$. However, individuals who were never married $(\mathrm{OR}=.5$, $95 \% \mathrm{CI}=.2-1.0)$ or divorced/separated/widowed $(\mathrm{OR}=.3,95 \% \mathrm{CI}=.2-.7)$ were significantly less likely to support the law than those who were married/common law relationship. We further conducted a post-hoc analysis in which we stratified the analysis by gender. In the multivariate analysis among men, being never married (as compared to being married/common law relationship) was significantly associated with not supporting the law $(\mathrm{OR}=.3,95 \% \mathrm{CI}=.1-.9)$ 
and being a nonsmoker as compared to a smoker was significantly associated with supporting the law $(\mathrm{OR}=7.7,95 \% \mathrm{CI}=2.7-22-2)$. Among women, those reporting being divorced/separated/widowed were significantly less likely to support the law than those who were married/common law relationship $(\mathrm{OR}=.3,95 \% \mathrm{CI}=.1-.9)$; whereas those with a postgraduate education (as compared to less than high school) $(\mathrm{OR}=4.4,95 \% \mathrm{CI}=1.1-17-3)$ and nonsmokers as compared to smokers $(\mathrm{OR}=4.6,95 \% \mathrm{CI}=1.4-14-9)$ were significantly more likely to support the law.

Table 3 presents the results of the associations between opinions regarding the smokefree law and support for the law in unadjusted and adjusted (for demographic variables and smoking status) logistic regression analyses. In the adjusted analyses, all opinions, with the exception of the belief that the smoke-free bylaw would increase stigma, were strongly associated with support for the smoke free bylaw. In posthoc stratified multivariate analysis (adjusting form demographic variables and smoking status) we obtained similar findings among males and females separately.

Discussion

The findings of our survey add to the limited number of published studies which provide evidence of support for smoke-free policies in outdoor recreational areas in Canada. The majority of participants ( $88.6 \%$ of non-smokers and $52 \%$ of smokers) supported the smoke-free bylaw in parks and on beaches in Vancouver. This finding contrasts with an earlier 2003 national survey in the United States that reported only a 25\% support for outdoor smoke-free laws among U.S. adults (in 2001 and 2002)[18]. However, our findings are more consistent with more recent studies such as a 2004 California study [9] which found 52\% of persons sampled $(\mathrm{n}=20,525)$ reported that they would support smoke-free policies in outdoor venues (including parks, 
beaches, outdoor sports stadiums, zoos and golf courses); a 2005 California study[19] in which $53.4 \%$ of respondents favoured smoke-free restrictions in outdoor public places; two 2008 New Zealand studies $[20,21]$ which found that $83 \%$ of surveyed park users $(n=587)$ approved of having a smoke-free park policy and $55 \%$ of participants from a national survey $(n=2349)$ supported smoke-free policies on beaches; a 2009 New Zealand study[22] that found 54.8\% of smoking participants $(n=1376)$ did not approve of no-smoking restrictions on life-guard patrolled beaches; and a 2009-2010 study $(n=6233)$ in Italy that found 64.6\% support for smoke-free public parks and gardens (77.4\% never-smokers, $61.8 \%$ former smokers, and 32.9\% current smokers) and 62.1\% support for smoke-free beaches (75.9\% never-smokers , 60.6 former smokers, and 31.2\% current smokers) [23]. These findings concur with the evidence that support for smoke-free legislations grows once these regulations are implemented [4]

We found that some demographic factors (i.e., being female, being of non- 'white or European' ancestry, being married or in a common-law relationship, having a higher education level, and not living with other smokers) were significantly associated with supporting the smoke-free bylaw. Other studies have also demonstrated unique demographic factors that are associated with support for smoke-free policies in various settings. For example, a study in North Carolina found that having an education level greater than high school is significantly predictive of supporting smoke-free venues in indoor work sites, restaurants, and bars [24]. A study in Italy found that compared to men, women were more likely to endorse smoke-free policies in some outdoor venues but this finding failed to reach significance in parks/gardens and beaches [23]. In the same study, higher education also predicted support for a smoke-free policy in beaches but was predictive of opposing a smoke-free policy in parks/gardens [23]. Another study in New South Wales found that living with a smoker and smoking status were significant predictors of 
not supporting a smoke-free law [21]. In addition, we found that marital status remained a significant predictor of supporting the smoke free bylaw even after adjusting for other variables. A 2008 study in New Zealand [21] found that marital status (being married vs. other) was significantly associated with support of smoke-free laws in univariate analysis, but failed to remain significant when adjusted with other variables (particularly living with a smoker and smoking status). However, other studies in Hong Kong and the U.S. have demonstrated that being married is often associated with support for smoke free restrictions in different venues [2527]

When controlling for demographic and smoking status, we found that all opinions regarding the smoke free law were significantly associated with support of the law, with the exception of the belief that the bylaws would increase stigma. These findings are similar to those of other studies assessing opinions regarding smoke free restrictions in parks and on beaches. For example, a study of city and county public officials in Colorado found that an important predictor of supporting a smoke-free policy in outdoor venues was related to the perception that it is a serious problem for non-smokers to breathe in other people's cigarette smoke [28]. Another study in the northeast of England found that among those individuals supporting a smoke-free policy in outdoor venues, the most cited reason was concern for the health of others $(57.5 \%, \mathrm{n}=332)$, whereas among those opposing the policy, the most cited reason was that such a policy would infringe on civil liberties $(49 \%, n=206)$ [29]. A more recent study (2007) in Minnesota found that reasons cited by the general public $(n=1,501)$ for support for smoke-free policies in parks included the reduction of litter (71\%), reducing opportunities for youth to smoke $(65 \%)$, to avoid SHS exposure (64\%), and to provide positive role models for youth (63\%) [15]. Hence, in developing and/or promoting smoke-free policies, issues concerning 
reducing litter, encouraging quitting, preventing youth initiation, and reducing SHS exposure should be emphasized through a sustained and well-funded public education program on the health and environmental benefits of outdoor smoke-free bylaws.

Although our analysis found that beliefs that the smoke free policy would increase stigma was not significantly related to support for the bylaw, several recent studies highlight that smoke free policies can result in unintended consequences, of which the stigmatization of smokers is of concern $[30,31]$. Furthermore, the infringement of smoke free bylaws on potential civil liberties and smokers' rights need to also be properly addressed to ensure wide support for such regulations [32]. Issues of smokers' rights have been shown in other studies to be important factors related to opposing smoke-free laws in outdoor venues [33]. This may be of particular import in a city such as Vancouver, with a low smoking rate [10] and increasingly the individuals left smoking are often among the marginalized- those with lower socioeconomic status, mental illnesses and/or addictions, those with aboriginal status[11, 12]. The potential effect of such smoke free laws on marginalized individuals in relation to civil liberties and stigmatization need to be further examined [34].

This study had some important limitations. First, the relatively low sample size of the study ( $\mathrm{N}=496$, which is $0.002 \%$ of Vancouver population aged 19 and older) gives a low statistical power to the study and does not permit the deriving of precise estimates from the analysis. Moreover, as this study was derived from one city in Canada (which already has among the lowest rates of smoking and highest rates of smoking restrictions in the country), the findings may not be generalizable to other jurisdictions given the unique policy context which exists in the city. However, the results of this study can inform the development of smoke-free policies in similar jurisdictions, as it demonstrates the importance of understanding how demographic 
similarities and differences within a community may influence support for such policies and regulations.

Second, the use of a telephone interview process (although we used random sampling) has a high likelihood of selection bias which could have resulted in our sample being over represented by women (61.1\%). Studies have indicated that women are more likely to support smoking restrictions $[35,36]$. Alternative methods of deriving opinion data from participants could have elicited more representative responses from participants. Future studies can consider the use of mailed surveys [15] or face-to-face surveys [20] at parks and on beaches to elicit greater response rates.

Third, although we found that individuals reporting a non-'white or European' ancestry were more likely to support smoke-free bylaws in outdoor parks and beaches, we did not have sufficient sample sizes to examine specific ethno-cultural differences. At best we can suggest that future studies may examine ethno-cultural perspectives in the development and implementation of smoke-free laws.

Fourth, we did not include income status of participants in our analyses. Although income status was asked, more than $20 \%$ of respondents refused to indicate their income. Nevertheless income status was not significantly associated with support for the smoke-free bylaw in bivariate analyses so it was not deemed a factor to include in the multivariate analyses.

Finally, due to the small sample size of smokers $(n=50)$, we could not adequately perform analyses to understand factors associated with support of the law stratified by smoking status. The low proportion of smokers in our sample could explain why overall support in our study was higher than found in other studies. Future studies among smokers may examine factors 
such as level of nicotine dependence, frequency of current smoking, smoking identity (e.g., social smokers, occasional smokers, heavy smokers), and demographic differences (i.e., gender, ethnicity, income, and education) in relation to supporting smoke-free bylaws.

Our study findings suggest strong support for the smoke-free bylaw prohibiting smoking in parks and on beaches in Vancouver, Canada among residents who visit parks and beaches. Despite the noted methodological limitations, the study findings further indicate that several demographic and attitudinal factors are associated with support for, and opposition to, a smokefree bylaw in parks and beaches. By understanding that smokers and non-smokers alike recognize the potential value of smoke-free bylaws in reducing litter, improving health and reducing SHS exposure, it is important for jurisdictions considering banning smoking in parks and on beaches to address attitudes which can promote or hinder the adoption of such bylaws among smokers and nonsmokers. Such findings can influence the health policy agenda within jurisdictions which are in the process of considering or adopting such smoke-free bylaws.

In conclusion, as a global leader in tobacco control policies and efforts [13], understanding the support for and effectiveness of smoke-free policies in outdoor areas within the Canadian context can inform policy directions for other jurisdictions across Canada and globally. Public opinion and response concerning the utility of public health measures which may have unintended consequences for specific vulnerable populations need to be adequately examined in the context of restrictions of smoking in outdoor public spaces. Hence, future studies should examine how diverse groups within the population are affected by smoke-free bylaws, thereby enhancing the development of sound and ethical public health policy that promotes equitable health benefits for all. 


\section{Acknowledgement:}

This study was funded by a Canadian Institute of Health Research (CIHR) grant \# GIR-112694 
References

[1] USDHHS. The Health Consequences of Involuntary Exposure to Tobacco Smoke: A Report of the Surgeon General., 2006.

[2] IARC Monographs on the Evaluation of Carcinogenic Risks to Humans Tobacco Smoke and Involuntary Smoking, Vol. 83: . Lyon, France: International Agency of Research on Cancer, 2004.

[3] Oberg M, Jaakkola MS, Woodward A, Peruga A, Prüss-Ustün A. Worldwide burden of disease from exposure to second-hand smoke: a retrospective analysis of data from 192 countries. Lancet 2011; 377:139-46.

[4] IARC Handbooks of Cancer Prevention, Tobacco Control. Evaluating the effectiveness of smoke-free policies, Vol. 13: . Lyon, France: International Agency of Research on Cancer, 2009.

[5] Thomson G, Wilson N, Edwards R. At the frontier of tobacco control: A brief review of public attitudes toward smoke-free outdoor places. Nicotine Tob Res 2009; 11:584-90.

[6] Hyland A, Barnoya J, Corral JE. Smoke-free air policies: past, present and future. Tob Control 2012; 21:154-61.

[7] Raphael J. The Calabasas smoking ban: A local ordinance points the way for the future of environmental tobacco smoke regulation. Southern California Law Review 2006; 80:393-424.

[8] Queensland Government. Summary of tobacco laws. 2009.

[9] Gilpin EA, Lee L, Pierce JP, Tang H, Lloyd J. Support for protection from secondhand smoke: California 2002. Tob Control 2004; 13:96.

[10] CTUMS. Canadian Tobacco Use Monitoring Survey (CTUMS) 2010. 2010.

[11] Huisman M, Kunst AE, Mackenbach JP. Inequalities in the prevalence of smoking in the European Union: comparing education and income. Preventive Medicine 2005; 40:756-64.

[12] Health Canada. First Nations, Inuit and Aboriginal Health: Tobacco., 2007.

[13] Sweanor D. A Canadian's perspective: Limits of tobacco regulation. William Mitchell Law Review 2008; 34:1595-604.

[14] Forsythe J. Smokefree outdoor public spaces: A community advocacy toolkit. Ottawa: Physicians for a Smoke-free Canada, 2010.

[15] Klein EG, Forster JL, McFadden B, Outley CW. Minnesota Tobacco-Free Park Policies: Attitudes of the General Public and Park Officials. Nicotine \& Tobacco Research 2007; 9:S49S55.

[16] Kennedy RD. Evaluation of the City of Woodstock's Outdoor Smoking By-law: A Longitudinal Study of Smokers and Non-Smokers. Psychology. Waterloo, ON: University of Waterloo, 2010:393.

[17] Hosmer D, Lemeshow S. Applied logistic regression. New York: Wiley, 2000.

[18] McMillen RC, Winickoff JP, Klein JD, Weitzman M. US adult attitudes and practices regarding smoking restrictions and child exposure to environmental tobacco smoke: Changes in the social climate from 2000-2001. Pediatrics 2003; 112:e55-60.

[19] Al-Delaimy W, White M, Trinidad D, Messer K, Mills A, Pierce J. The California Tobacco Control Program: can we maintain the progress? Results from the California Tobacco Survey (CTS), 1990-2005. Volume 2. California Department of Public Health., 2008. 
[20] Stevenson A-M, Bradshaw R, Cook J, Cunningham R, Riddick L, Miller R, Edwards R, Wilson N, Thomson G. Majority of smokers and non-smokers in favour of smokefree parks in New Zealand. The New Zealand Medical Journal 2008; 121:108-9.

[21] Walsh RA, Paul CL, Tzelepis F, Stojanovski E, Tang A. Is government action out-of-step with public opinion on tobacco control? Results of a New South Wales population survey. Australian and New Zealand Journal of Public Health 2008; 32:482-8.

[22] Wilson N, Blakely T, Edwards R, Weerasekera D, Thomson G. Support by New Zealand smokers for new types of smokefree areas: national survey data. The New Zealand Medical Journal 2009; 122:80-9.

[23] Gallus S, Rosato V, Zuccaro P, Pacifici R, Colombo P, Manzari M, La Vecchia C. Attitudes towards the extension of smoking restrictions to selected outdoor areas in Italy. Tobacco Control 2012; 21:59-62.

[24] Maguire RL, Brinkley J, Mansfield C. Attitudes toward smoking restrictions in work sites, restaurants, and bars among North Carolinians. N C Med J 2010; 71:511-8.

[25] Lam TH, Janghorbani M, Hedley AJ, Ho SY, McGhee SM, Chan B. Public opinion on smoke-free policies in restaurants and predicted effect on patronage in Hong Kong. Tobacco Control 2002; 11:195-200.

[26] Shelley D, Fahs MC, Yerneni R, Qu J, Burton D. Correlates of Household Smoking Bans Among Chinese Americans. Nicotine \& Tobacco Research 2006; 8:103-12.

[27] Osypuk TL, Acevedo-Garcia D. Support for Smoke-Free Policies: A Nationwide Analysis of Immigrants, US-Born, and Other Demographic Groups, 1995-2002. American Journal of Public Health 2010; 100:171-81.

[28] Andersen PA, Buller DB, Voeks JH, Borland R, Helme D, Bettinghaus EP, Young WF. Predictors of Support for Environmental Tobacco Smoke Bans in State Government. American Journal of Preventive Medicine 2006; 30:292-9.

[29] Ahmed S, Aujayeb A, Cowens E, Evans A, Gent F, Adams J, Heywood P, White M. Would the public support a ban on smoking in public place? - A survey of local opinion in the North East of England. McGill Journal of Medicine 2004; 8:15-20.

[30] Stuber J, Galea S, Link BG. Smoking and the emergence of a stigmatized social status. Social Science \& Medicine 2008; 67:420-30.

[31] Ritchie D, Amos A, Martin C. "But it just has that sort of feel about it, a leper"-Stigma, smoke-free legislation and public health. Nicotine \& Tobacco Research 2010; 12:622-9.

[32] Chapman S. Going too far- exploring the limits of smoking regulations. William Mitchell Law Review 2008; 34:1605-20.

[33] Hyslop B, Thomson G. Smokefree outdoor areas without the smoke-police: the New Zealand local authority experience. The New Zealand Medical Journal 2009; 122:67-79.

[34] Warner J. Smoking, Stigma and Human Rights in Mental Health: Going up in Smoke? Social Policy and Society 2009; 8:275-86.

[35] Gallus S, Rosato V, Zuccaro P, Pacific R, Colombo P, Manzari M, La Veccia C. Attitudes towards the extension of smoking restrictions to selected outdoor areas in Italy. Tobacco Control 2012; 21:59-62.

[36] Hitchman S, Fong GT, Zanna MP, Hyland A, Bansal-Travers M. Support and correlates of support for banning smoking in cars with children: findings from the ITC Four Country Survey. European Journal of Public Health 2010; 21:360-5. 


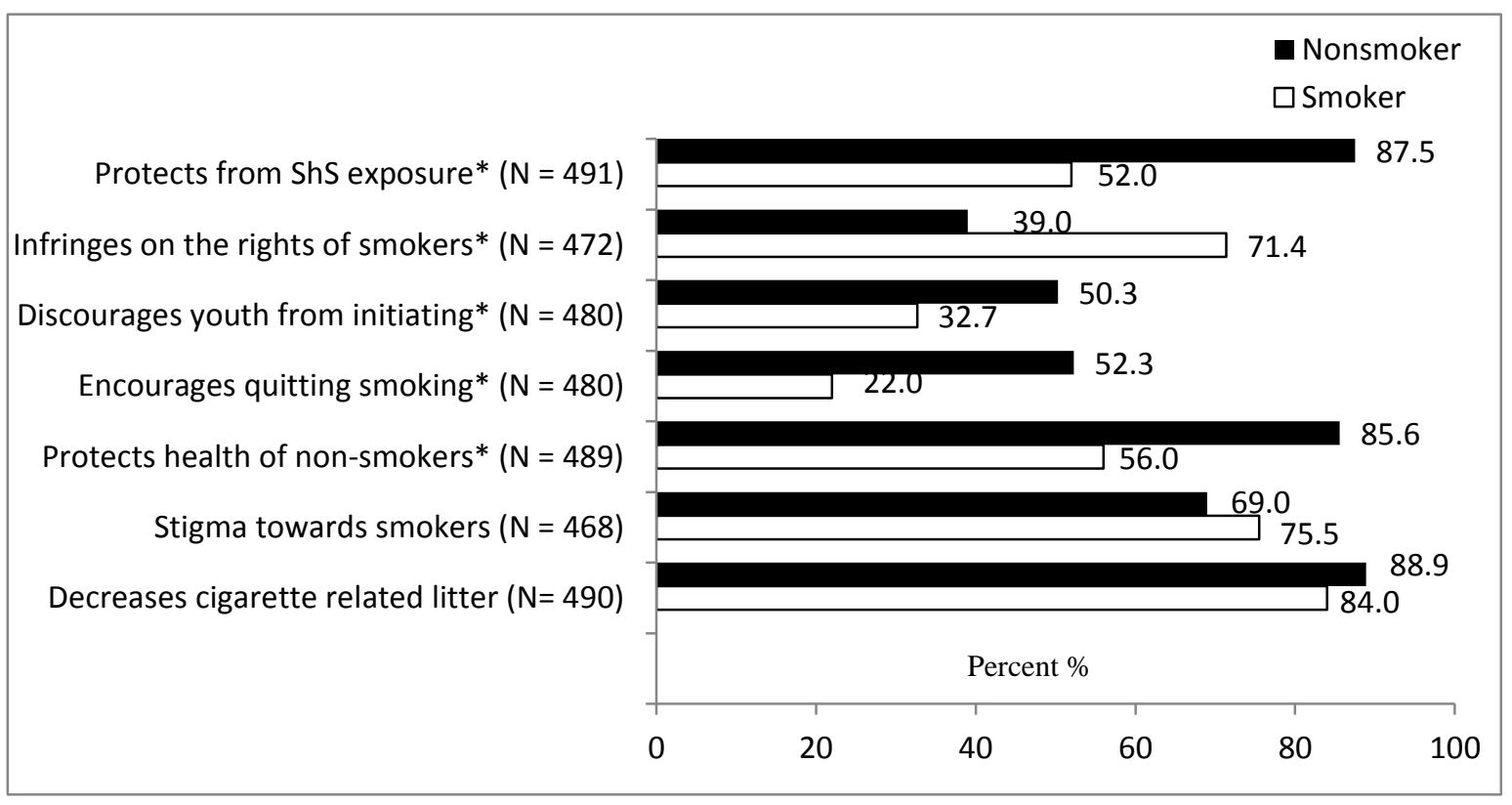

Figure 1. Opinions regarding smoke-free law by smoking status. * indicates significant differences between smokers and nonsmokers 
Table 1. Sample Characteristics

\begin{tabular}{|c|c|c|c|c|c|c|c|}
\hline & \multicolumn{2}{|c|}{$\begin{array}{c}\text { Total Sample } \\
(\mathrm{N}=496)\end{array}$} & \multicolumn{2}{|c|}{$\begin{array}{l}\text { Support } \\
(\mathrm{n}=421)\end{array}$} & \multicolumn{2}{|c|}{$\begin{array}{c}\text { Opposed } \\
(\mathrm{n}=75)\end{array}$} & \multirow{2}{*}{$\begin{array}{c}\text { Difference }^{* *} \\
\chi^{2}(\mathrm{df}), \mathrm{p}\end{array}$} \\
\hline & $\mathrm{n}$ & $\%$ & $n$ & $\%$ & $n$ & $\%$ & \\
\hline Gender & & & & & & & $12.6(1),<.0001$ \\
\hline Female & 303 & 61.1 & 271 & 64.4 & 32 & 42.7 & \\
\hline Male & 193 & 38.9 & 150 & 35.6 & 43 & 57.3 & \\
\hline Age $(\mathrm{N}=485)$ & & & & & & & $2.3(2), .314$ \\
\hline $18-34$ & 50 & 10.3 & 41 & 10.0 & 9 & 12.3 & \\
\hline $35-54$ & 212 & 43.7 & 186 & 45.1 & 26 & 35.6 & \\
\hline 55 and older & 223 & 46.0 & 185 & 44.9 & 38 & 52.1 & \\
\hline \multicolumn{8}{|l|}{ Ethnicity $(\mathrm{N}=470)$} \\
\hline White or European ancestry & 366 & 77.9 & 304 & 76.0 & 62 & 88.6 & $7.4(7), .391$ \\
\hline Black or African Ancestry & 3 & 0.6 & 3 & 0.8 & 0 & 0.0 & \\
\hline First Nations & 4 & 0.9 & 4 & 1.0 & 0 & 0.0 & \\
\hline South East Asian (i.e., Indian, Pakistani, Bangladesh) & 18 & 3.8 & 15 & 3.8 & 3 & 4.3 & \\
\hline East Asian (i.e., Chinese, Taiwanese, Korean, Filipino etc.) & 70 & 14.9 & 65 & 16.2 & 5 & 7.1 & \\
\hline Middle Eastern & 5 & 1.1 & 5 & 1.2 & 0 & 0.0 & \\
\hline Hispanic or from South America & 3 & 0.6 & 3 & 0.8 & 0 & 0.0 & \\
\hline Other & 1 & 0.2 & 1 & 0.2 & 0 & 0.0 & \\
\hline Marital Status $(\mathrm{N}=470)$ & & & & & & & $9.6(2), .008$ \\
\hline Never married & 82 & 17.4 & 66 & 16.6 & 16 & 21.9 & \\
\hline Divorced/Separated/Widowed & 96 & 20.4 & 73 & 18.4 & 23 & 31.5 & \\
\hline Married, living with spouse/common law & 292 & 62.1 & 258 & 65.0 & 34 & 46.6 & \\
\hline Education status ( $\mathrm{N}=479$ ) & & & & & & & $6.7(3), .084$ \\
\hline Less than High school/High school & 61 & 12.7 & 46 & 11.2 & 15 & 21.4 & \\
\hline Some university or Community College & 48 & 10.0 & 40 & 9.8 & 8 & 11.4 & \\
\hline Community College/University Graduate & 233 & 48.6 & 201 & 49.1 & 32 & 45.7 & \\
\hline Post Graduate degree & 137 & 28.6 & 122 & 29.8 & 15 & 21.4 & \\
\hline Living with other smokers ( $N=495$ ) & & & & & & & $2.0(1), .154$ \\
\hline Yes & 50 & 10.1 & 39 & 9.3 & 11 & 14.7 & \\
\hline No & 445 & 89.9 & 381 & 90.7 & 64 & 85.3 & \\
\hline Smoking Status & & & & & & & $46.8(1),<.0001$ \\
\hline Non-smoker & 446 & 89.9 & 395 & 93.8 & 51 & 68.0 & \\
\hline Smoker & 50 & 10.1 & 26 & 6.2 & 24 & 32.0 & \\
\hline
\end{tabular}

** Chi-square analysis (or Fisher's exact tests for variables with small cell numbers) employed to examine differences between nonsmokers and smokers in demographic factors 
Table 2.Two-step multivariate logistic regression analyses of demographic variables associated with support for a smoke-free law (support vs. oppose) in parks and beaches.

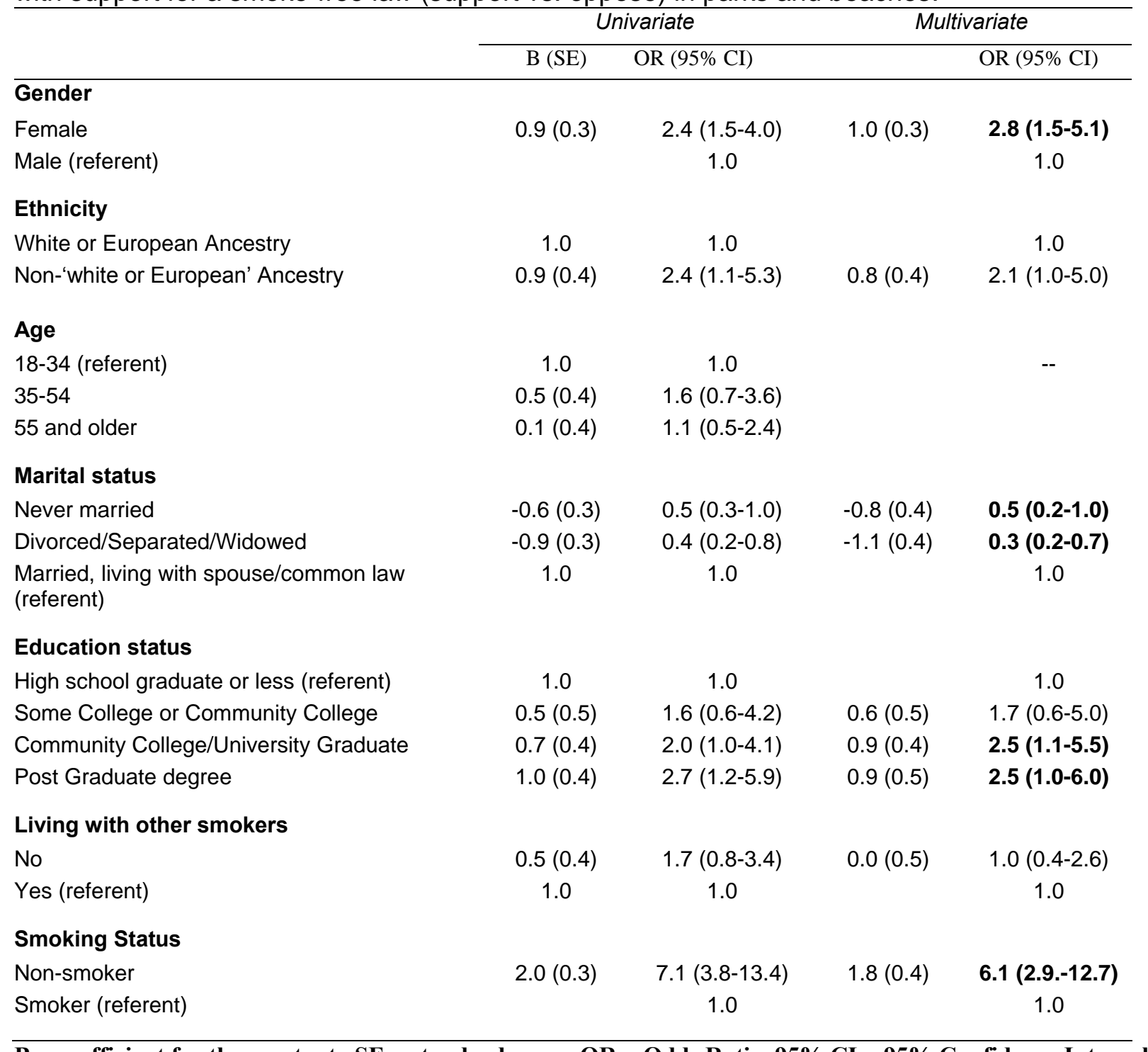

$\bar{B}=$ coefficient for the constant, $\mathrm{SE}=$ standard error, $\mathrm{OR}=$ Odds Ratio, $95 \% \mathrm{CI}=95 \%$ Confidence Interval 
Table 3. Unadjusted and adjusted analysis of the association between opinions related with the smoke-free law and support of the smoke free law

\begin{tabular}{|c|c|c|c|c|c|}
\hline & & & nadjusted & & djusted* \\
\hline & $\mathrm{n}(\%)$ & B (SE) & $\mathrm{OR}(95 \% \mathrm{CI})$ & B (SE) & OR $(95 \% \mathrm{CI})$ \\
\hline Bylaws decreases litter $(n=490)$ & & & & & \\
\hline Strongly/Somewhat Believe & $385(92.8)$ & $2.0(0.3)$ & $7.2(4.0-13.2)$ & $2.1(0.4)$ & $8.1(3.9-17.0)$ \\
\hline Strongly/Somewhat Disbelieve (referent) & $30(7.2)$ & & 1.0 & & 1.0 \\
\hline Bylaws increase stigma $(n=468)$ & & & & & \\
\hline Strongly/Somewhat Believe & 269 (68.3) & $-0.4(0.3)$ & $0.6(.4-1.1)$ & $1.4(0.4)$ & $.7(.3-1.3)$ \\
\hline Strongly/Somewhat Disbelieve (referent) & $125(31.7)$ & & 1.0 & & 1.0 \\
\hline $\begin{array}{l}\text { Bylaws protect the health of non- } \\
\text { smokers and children }(n=489)\end{array}$ & & & & & \\
\hline Strongly/Somewhat Believe & $388(93.5)$ & $4.0(0.3)$ & $52.1(26.5-102.5)$ & $3.9(0.4)$ & $50.7(22.3-114.7)$ \\
\hline Strongly/Somewhat Disbelieve (referent) & $27(6.5)$ & & 1.0 & & 1.0 \\
\hline Bylaws will encourage quitting $(n=480)$ & & & & & \\
\hline Strongly/Somewhat Believe & $224(54.8)$ & $1.8(0.3)$ & $6.0(3.1-11.4)$ & $1.6(0.5)$ & $4.9(2.3-10.2)$ \\
\hline Strongly/Somewhat Disbelieve (referent) & $185(45.2)$ & & 1.0 & & 1.0 \\
\hline $\begin{array}{l}\text { Bylaws discourage youth initiation } \\
(n=480)\end{array}$ & & & & & \\
\hline Strongly/Somewhat Believe & $216(53.3)$ & $1.4(0.3)$ & $3.9(2.2-6.9)$ & $1.1(0.3)$ & $3.1(1.6-5.9)$ \\
\hline Strongly/Somewhat Disbelieve (referent) & $189(46.7)$ & & 1.0 & & 1.0 \\
\hline $\begin{array}{l}\text { Bylaws infringe on smokers' rights } \\
(n=472)\end{array}$ & & & & & \\
\hline Strongly/Somewhat Believe & $139(34.8)$ & $-2.3(0.3)$ & $0.1(.0-0.2)$ & $-2.2(0.4)$ & $.1(.1-.2)$ \\
\hline Strongly/Somewhat Disbelieve (referent) & $261(65.2)$ & & 1.0 & & 1.0 \\
\hline $\begin{array}{l}\text { Bylaw will protect from SHS exposure } \\
(n=491)\end{array}$ & & & & & \\
\hline Strongly/Somewhat Believe & 390 (93.3) & $3.5(0.3)$ & $32.3(17.2-60.6)$ & $3.5(0.4)$ & $32.4(15.3-68.8)$ \\
\hline Strongly/Somewhat Disbelieve (referent) & $28(6.7)$ & & 1.0 & & 1.0 \\
\hline
\end{tabular}

$\mathrm{B}=$ coefficient for the constant, $\mathrm{SE}=$ standard error, $\mathrm{OR}=$ Odds Ratio, $95 \% \mathrm{CI}=\mathbf{9 5} \%$ Confidence Interval

*All opinion variables are adjusted for demographic variables (Gender, ethnicity, age, marital status, education status, living with other smokers, and smoking status). All adjusted models demonstrated good fit using the HosmerLemeshow goodness of fit test. 